\title{
PSYCHOLOGICAL HEALTH RELATED QUALITY OF LIFE IN PAKISTANI PHYSICAL
} THERAPISTS

Rehab House Officer, Helping Hand Institute of Rehabilitation Sciences, Mansehra Pakistan.

Rehab House Officer. Isra Institute of Rehabilitation Sciences, Isra University Islamabad, Pakistan

Assistant Professor Department of Sociolog. Allama labal Open University Islamabad. Pakistan

Correspondence

Nimra llyas Bhutta

Rehab House Officer, Helping Hand Institute of

Rehabilitation Sciences, Mansehra Pakistan.

E-mail: nimrailyasbhutta@yahoo.com

Received on: 09-06-2019

Revision on: 13-10-2019

Published on: 31-12-2019

Citation

Bhutta NI, Sheikh A, Haider SI. Psychological

health related quality of life in pakistani

physical therapists. T Rehabili. J.

2019:03(02);116-120. soi: 21-2017/re trjvol03iss02p116
Nimra llyas Bhutta ${ }^{1}$ : Analysis \& interpretation of data, writing; Revised and Accountable for all aspects Aneeta Sheikh ${ }^{2}$ : Analysis \& interpretation of data, writing; Revised and Accountable for all aspects Syed Imran Haider ${ }^{3}$ : Writing; Revised and Accountable for all aspects

\section{ABSTRACT}

Objectives: To find quality of life (QOL) related to psychological health and its associated factors in Pakistani physical therapists. Mathodology: A cross sectional-analytical study was conducted among Pakistani physical therapists, working in different teaching institutes and hospitals. The sample size was $(n=464)$ qualified physical therapists age between 22-50 years selected through convenient sampling technique. Data was collected through general demographic questionnaire including age, gender qualification, marital status, job type, job nature, financial, family and health issues, job satisfaction, overall satisfaction, and for psychological health WHO Quality of Life (WHO-QOL) was used. Data was analyzed by using SPSS version 21 and the results were presented as mean \pm SD, frequency $(n)$ and percentages (\%) of physical therapist according to their psychological health and p-value and chi-square test was used to identify association between variables. Results: The mean age of study participant was $27.02 \pm 3.79$ and mean psychological health score was $36.49 \pm 17.38$ that showed that average population of PTs had poor psychological health. The psychological health showed significant association $(p \leq 0.05)$ with gender, nature of job, financial issues, health issues and salary satisfaction. Conclusion: The majority of physical therapists have poor psychological health. The male gender, PTs working in both clinical and academic settings, financial issues, family issues their health status and unsatisfied job contribute in poor quality of life related to psychological health.

Keywords: Physical therapist, psychological health, quality of life

\section{INTRODUCTION}

Psychological illnesses are among common psychiatric issues globally and depression, anxiety and stress are very common. ${ }^{1}$ Psychological health is one of the main domains of quality of life, which is the perception of an individual's life in accordance to one's anticipation, goals and purpose in relation to norms and culture of an organization where one lives. ${ }^{2}$

HR-QoL is multidimensional and dynamic, relatively new concept, and self-reported outcome. It covers all aspects of health including physical, social and role functioning as well as mental health. Healthy peoples can communicate more effectively and having good self-respect, being more creative and enthusiastic to work. ${ }^{3}$ The HRQoL is assessed through various tools, by means of especially structured disease specific as well as standardized questionnaires which are validated and reliable. Although, Enormous studies have been conducted to evaluate health related quality of life and to improve it by identifying appropriate treatments in different disease conditions, but there is dearth of literature regarding HRQoL in medical specialists. ${ }^{4}$

Physical therapists being health care professionals have a job to diagnose and treat disorders related to movements, demanding high working hours and physical abilities. ${ }^{5}$ Professional burnout, emotional fatigue, low sense of individual achievement, depersonalization, affected proficiency, decrease in quality of patient care, increased therapeutic errors, destroyed relationship, premature retirement, suicidal ideation and substance abuse are common among physical therapists, occupational therapists and physicians due to work overload. ${ }^{6-9}$

A study reported that in physical therapist the excessive work related stress is about $53 \%{ }^{10}$ Moderate burnouts and musculoskeletal disorders are associated with high level jobs in physical therapists, resulting in more sickness leaves and health care consults. ${ }^{11}$ A study conducted by Liaqat $M$ et al on physical health related to quality of life in Pakistani physical therapist, reported that depression, anxiety and stress significantly associated with poor physical health. ${ }^{5}$ This study provides strong basis for the need to assess Quality of life related to psychological health and exploring potential contributing factors. Thus, this study aimed to find out the psychological health related QOL and its associated factors in physical therapists of Pakistan.

\section{METHODOLOGY}

The cross sectional-analytical study was conducted among physical therapists of Pakistan working in

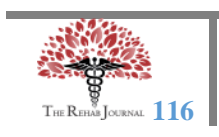


various teaching institutes and hospitals. The sample size was $n=464$ decided by Rao soft sample size calculator with error margin being $5 \%$, which was collected through convenient sampling technique. The Physical therapists those having bachelors and Doctor of physical therapy (DPT) degree, age limit of 22-50 years were included in the study. Whereas, PT technicians/technologists or quacks were excluded from study. The data was collected regarding PTs age, gender, qualification, marital status, job type, job nature, financial and family issues, health status, job and salary satisfaction and overall satisfaction, and psychological health related quality of life was assessed through WHO Quality of Life (WHO-QOL) questionnaire. The questionnaire was also developed on Google form and distributed to Physical therapist through emails. The Informed consent was obtained from the respondents before data collection. Confidentiality and anonymity of study participants was maintained in research. The data was presented in form of frequency, percentages, mean $\pm S D$, and $p$-value. To find association between variable chi-square test was used with alpha level 0.05. SPSS version 21 was used for data analysis.

\section{RESULTS}

The results showed that mean age of study participant was $27.02 \pm 3.79$ and mean score of quality of life related to psychological health was $36.49 \pm 17.38$ that showed that majority of PTs had poor psychological health. The detail frequency distribution of PTs regarding psychological health can be seen in Figure 1.

The psychological health showed significant association with gender $\left(X^{2}=11.07, p=0.020\right)$, nature of job $\left(X^{2}=28.36, p<0.001\right)$, financial issues $\left(X^{2}=9.00, p<0.001\right)$, family issues $\left(X^{2}=5.59, p=0.01\right)$, health issues $\left(X^{2}=16.84, p=0.02\right)$ and Job satisfaction $\left(X^{2}=5.40, p=0.01\right)$. The psychological health found poor among Physical therapists those who were divorced $(33.63 \pm 8.94)$ and very poor among those working in semi-government setups (33.49 \pm 18.22$)$ and those who were not satisfied with their job $(34.62 \pm 17.20)$. For detail description of results see table 1 .

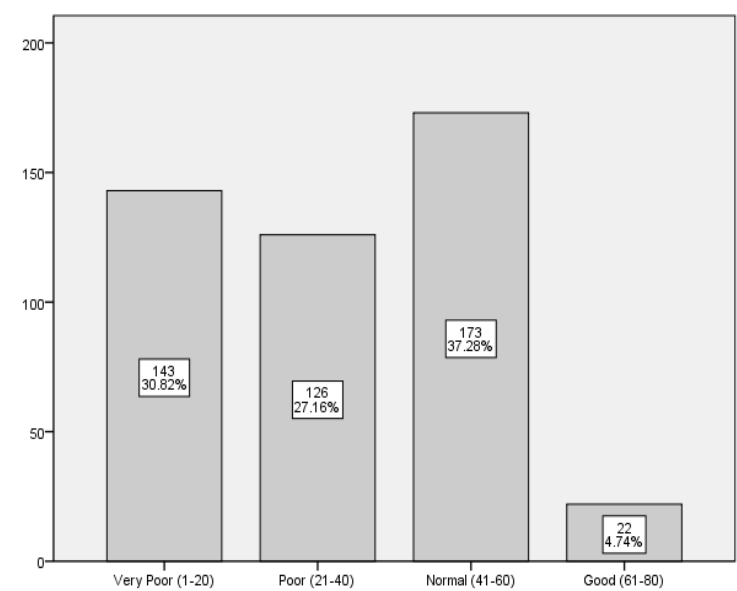

Figure 1: PTs distribution in relation to Psychological Health

\section{DISCUSSION}

The objective of the present study was to find out the quality of life related to psychological health and factors affecting it in Pakistani Physical therapist. The key findings suggested that average psychological health in PTs was poor. It was also found that Psychological health was poorly affected in male gender, PTs working in both clinical and academic settings, having financial and family issues, moreover health status and job satisfaction also found to have an impact on psychological health.

Numbers of studies in Asian and western countries have been published assessing the stress, mental health, depression and its related variables in different health care professionals. ${ }^{12-17}$ But few studies have been found which addresses the work related stress in qualified physical therapists. $8,10,18$ The key findings of the present study highlighted that about $30.8 \%$ PTs reported very poor mental health, which is well supported by a study investigated the mental health among undergraduate physiotherapy students of Sindh, reporting $48 \%$ depression, $68.5 \%$ anxiety and $53.2 \%$ stress in physiotherapist students of Sindh, Pakistan. ${ }^{1}$ Although it is evident from previous studies that higher stress, depression and burnout rates are experienced by medical students. ${ }^{19-23}$ 
Table 1: Psychological Health Related QOL in Physical Therapists

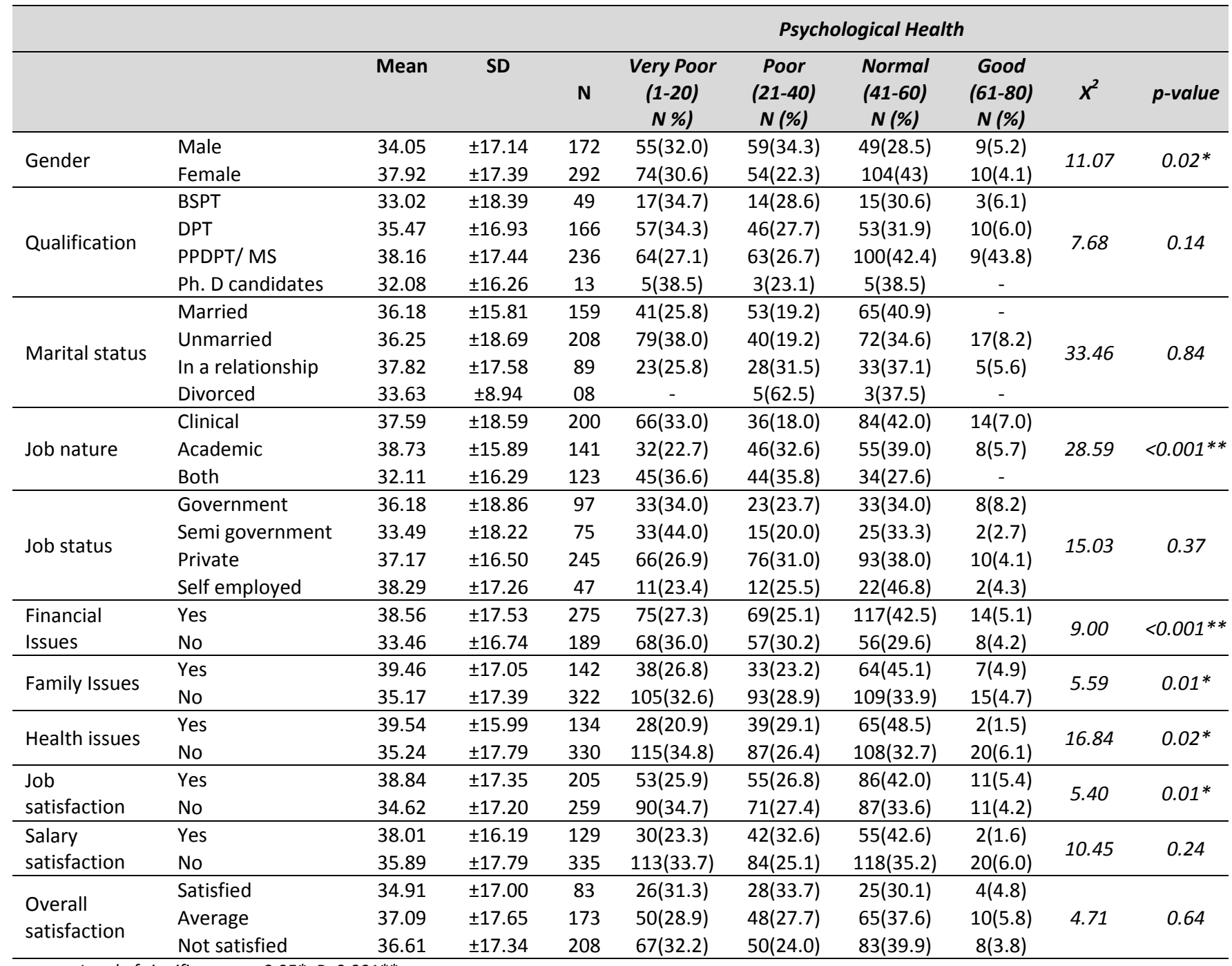

Level of significance: $p \leq 0.05^{*}, P<0.001^{* *}$

Gender showed significant association with psychological health related quality of life. The male showed poor psychological health related QoL as compare to female. The findings reported by marc $A$ et al. in their study oppose the findings of current study that female gender, young age and high job demands are at higher risk for turnover and job strains.18 Moreover, A study reported that job related burnout is more prevalent in women physicians, ${ }^{24}$ which contradicts findings of present study, but according to the literature found that working men of Pakistan experiences gender role strain as their role is being the head of the family, to act as gentle man in the society and to adopt the profession. ${ }^{25}$ This might be the reason Pakistani male physical therapist experiences more mental issues then female PTs as they has to obey above mentioned roles.
The current study showed that Job nature of PTs is significantly associated with psychological health. Physical therapist working in both clinical and academic setting showed poor psychological health related QoL than PTs working in clinical or academic setting, which is evident by previous study that high level of job strain is experienced by physical therapists. ${ }^{18}$ This issue is difficult to address due to interviews and group studies emphasis. However, it is evident that doctors are at greater risk of stress-related problems and psychological illness, therefore, are more vulnerable to substance abuse. ${ }^{26,27}$ Psychiatric illness experienced by doctors is reported about 3 $10 \%$ among all other health related illnesses. Surprisingly it is sad to report that medical professionals go through one or more of "the three Ds" depression, drugs and drink. ${ }^{28}$ While, in present study $22.7 \%$ and $32.6 \%$ PTs were those 
working only on academic side had very poor and poor psychological health, respectively, as mental health is affected more in those working on academic side. ${ }^{5}$ Among $33 \%$ and $18 \%$ clinicians had very poor and poor psychological health respectively. Medical professionals may have good physical but poor psychological health, which may decrease their ability to provide proper care to their patients. ${ }^{29,30}$

Financial issue among PTs also showed significant association with poor psychological health. Previously a study conducted among physical therapist of Poland regarding life satisfaction and burnout related to their work revealed that financial issues among females and lack of free time among male physiotherapist induces work related burnout. ${ }^{31}$ Furthermore, it is reported in a study that economic recession and financial crisis leads to psychological health issues, suicide and depressions, requiring mental health services. ${ }^{32,33}$ In Pakistan Physical therapist salary starting is about 26,000 PKR per month, and may range to PKR 190,000 per month as per experience and qualification based increments. The financial crisis in Pakistan may lead physical therapist to be mentally disturbed for their basic needs and satisfaction. This might be the reason that current study reported about $33.7 \%$ PTs were not satisfied with their salary had very poor mental health.

Present study disclosed that family issues have significant impact on psychological health, similarly reported in a study conducted among chines doctor reported that work-family conflict was highly associated with work related stressors. ${ }^{34}$ Similarly study reported that work family conflict among patient care workers may lead to psychological distress and sleep insufficiency and it may have negative impact on person's quality of life. $^{35,36}$

The current study showed health issues also showed significant association with poor psychological health. A study conducted by Liaqat $M$ et al reported poor physical health contributes to mental health issues such as depression, stress and anxiety. ${ }^{5}$

The present study demonstrated that $34.5 \%$ PTs who were not satisfied with their job reported very poor mental health, which may be associated with prolong working hours, physical and mental exertions, and feel they are overworked, similar findings are reported by HGB Speakman et al in their study. ${ }^{37}$ Neil $D$ et al reported that the excessive work related stress called as burnout, is evident in physical therapists ${ }^{10}$. A previous study revealed that PTs stated that their job is stressful, $13.8 \%$ were those worked in public center and $25.5 \%$ working in private sector have work related burnout. $^{38}$ Furthermore, higher suicidal rate is reported in doctors as compared to general population. $^{30,39,40}$

The present study demonstrated that, 44\% PTs employed in semi-government institutes were having poor mental health. Stress, psychiatric morbidities, illness and high suicidal rates were reported by previous studies in doctors associating with greater $\mathrm{BMI}$, alcohol use and prevalent smoking ${ }^{41,42}$

The current study lack the identification of comorbidities and effect of mental issues on performances of physical therapist and relation of mental health with working years.

\section{CONCLUSION}

Majority of physical therapists had poor psychological health. Psychological health was found to have significant association with female gender, health status, financial and family issues, and job satisfaction. Psychological health is affected by increased workload, especially in those working in both clinical and academic setups. In future studies can be performed in larger sample size.

\section{REFERENCES}

1. Syed A, Ali SS, Khan M. Frequency of depression, anxiety and stress among the undergraduate physiotherapy students. Pak. J. Med. Sci. 2018;34(2):468.

2. Group W. The World Health Organization quality of life assessment (WHOQOL): position paper from the World Health Organization. Soc. Ssi. \& Med. 1995;41(10):1403-9.

3. Ahmad AB. Pengaruh karakteristik demografi dan iklim organisasi terhadap quality of work life (qwl) dosen politeknik kesehatan banjarmasin. J. Waw. Manaj.. 2015;3(3):229-42.

4. Kotlo A, Maram A, Muragundi PM, Janodia M, Ligade V. Health Related Quality of Life among Medical Representatives. J. Young Pharmacists. 2016;8(1).

5. Liaqat M, Kanwal R, Munir S. Physical health related quality of life in pakistani physical therapists. T. Rehab. J. 2018;2(02).

6. Shanafelt TD, Boone S, Tan L, Dyrbye LN, Sotile W, Satele $D$, et al. Burnout and satisfaction with work-life balance among US physicians relative to the general US population. Arch. inter. Med. 2012;172(18):1377-85. 
7. Scutter S, Goold M. Burnout in recently qualified physiotherapists in South Australia. Aus J Phys Ther. 1995;41(2):115-8.

8. Balogun JA, Titiloye $V$, Balogun A, Oyeyemi A, Katz J. Prevalence and determinants of burnout among physical and occupational therapists. J Allied Health. 2002;31(3):131-9.

9. Pustułka-Piwnik U, Ryn ZJ, Krzywoszański $Ł$, Stożek J. Burnout syndrome in physical therapists-demographic and organizational factors. Med Pr. 2014;65(4):453-62.

10. Schuster ND, Nelson DL, Quisling C. Burnout among physical therapists. Phys Ther. 1984;64(3):299-303.

11. Cromie JE, Robertson VJ, Best MO. Work-related musculoskeletal disorders in physical therapists: prevalence, severity, risks, and responses. Phys Ther. 2000;80(4):336-51.

12. Grover S, Sahoo S, Bhalla A, Avasthi A. Psychological problems and burnout among medical professionals of a tertiary care hospital of North India: A cross-sectional study. Ind J Psych. 2018;60(2):175.

13. Low ZX, Yeo KA, Sharma VK, Leung GK, McIntyre RS, Guerrero A, et al. Prevalence of burnout in medical and surgical residents: a meta-analysis. Int J Environ Res Public Health. 2019;16(9):1479.

14. Liu Y, Zhang J, Hennessy DA, Zhao S, Ji H. Psychological strains, depressive symptoms, and suicidal ideation among medical and non-medical staff in urban china. J Affect Disord. 2019;245:22-7.

15. Maharaj S, Lees T, Lal S. Prevalence and risk factors of depression, anxiety, and stress in a cohort of Australian nurses. Int J Environ Res Public Health. 2019;16(1):61.

16. Martin F, Poyen D, Bouderlique E, Gouvernet J, Rivet B, Disdier $\mathrm{P}$, et al. Depression and burnout in hospital health care professionals. Int J Occup Environ Health. 1997;3(3):204-9.

17. Kaviani $H$, Khaghanizade $M$. The relationship between burnout and mental health among nurses. Tehran Uni Med J. TUMS Publications. 2007;65(6):65-75.

18. Campo MA, Weiser S, Koenig KL. Job strain in physical therapists. Phys Ther. 2009;89(9):946-56.

19. Dahlin $M$, Joneborg N, Runeson B. Stress and depression among medical students: A cross-sectional study. Med Educ. 2005;39(6):594-604.

20. Aktekin M, Karaman $T$, Senol YY, Erdem S, Erengin H, Akaydin M. Anxiety, depression and stressful life events among medical students: a prospective study in Antalya, Turkey. Med Educ. 200;35(1):12-7.

21. Dyrbye LN, Thomas MR, Shanafelt TD. Systematic review of depression, anxiety, and other indicators of psychological distress among US and Canadian medical students. Acad Med. 2006;81(4):354-73.

22. Darragh AR, Huddleston W, King P. Work-related musculoskeletal injuries and disorders among occupational and physical therapists. Am J Occup Ther. 2009;63(3):351-62.

23. Volpe $U$, Ventriglio $A$, Bellomo $A$, Kadhum $M$, Lewis $T$, Molodynski A, et al. Mental health and wellbeing among Italian medical students: A descriptive study. Int Rev Psychiatry. 2019;31(7-8):569-73.

24. Templeton K, Bernstein CA, Sukhera J, Nora LM, Newman C, Burstin $\mathrm{H}$, et al. Gender-Based Differences in Burnout: Issues Faced by Women Physicians. NAM Perspectives. 2019.

25. Adil, F., Shahed, S., \& Arshad, H. (2017). The burden of being a man in a patriarchal society. J Arts Socia Sci, 4(2), 57-70.

26. Vieira ER, Svoboda S, Belniak A, Brunt D, Rose-St Prix C, Roberts $L$, et al. Work-related musculoskeletal disorders among physical therapists: an online survey. Disabili Rehabili. 2016;38(6):552-7.
27. Wilhelmus Johannes Andreas G, Wernstedt P, Campo M. Work-related musculoskeletal disorders in female Swedish physical therapists with more than 15 years of job experience: prevalence and associations with work exposures. Physiother Theory Pract. 2011;27(3):213-22.

28. Kay MP, Mitchell GK, Del Mar CB. Doctors do not adequately look after their own physical health. Med J Aust. 2004;181(7):368-70.

29. S Su JA, Weng HH, Tsang HY, JL Wu. Mental health and quality of life among doctors, nurses and other hospitals staff. Stress Med. 2009;35(5):423-30.

30. Pilowski L, O'Sullivan G. Mental illness in doctors. BMJ: Br. Med. J. 1989;298(6669):269.

31. Śliwiński Z, Starczyńska M, Kotela I, Kowalski T, KryśNoszczyk K, Lietz-Kijak D, et al. Life satisfaction and risk of burnout among men and women working as physiotherapists. Int J Occup Med Environ Health. 2014;27(3):400-12.

32. Shrivastava A, Lodha P, De Sousa A, Singh N. Economic Recession and Mental Health: An Analysis. Adv Psychia. 2019; 679-95.

33. Simpson LA, Grant L. Sources and magnitude of job stress among physicians. J Behav Med. 1991;14(1):27-42.

34. Wang Y, Liu L, Wang J, Wang L. Work-family conflict and burnout among Chinese doctors: the mediating role of psychological capital. J Occup Health. 2012;54(3):232-40.

35. Jacobsen HB, Reme SE, Sembajwe G, Hopcia K, Stoddard AM, Kenwood C, et al. Work-family conflict, psychological distress, and sleep deficiency among patient care workers. Workplace Health Saf. 2014;62(7):282-91.

36. Higgins CA, Duxbury LE, Irving RH. Work-family conflict in the dual-career family. Organi Behav Human Decisi Process. 1992;51(1):51-75.

37. Speakman HG, Pleasant JM, Sutton GB. The job satisfaction of physical therapists. Phys Res Int. 1996;1(4):247-54.

38. Pavlakis A, Raftopoulos V, Theodorou M. Burnout syndrome in Cypriot physiotherapists: a national survey. BMC Health Serv Res. 2010;10(1):63.

39. Tyssen R, Vaglum P. Mental health problems among young doctors: an updated review of prospective studies. Harvard Rev Psychi. 2002;10(3):154-65.

40. Elliot L, Tan J, Norris S. Themental Health of Doctors: A Systematic Literature Review: Beyond Blue; 2010.

41. Bansal R, Katyal R, Haji SA, Kumari R. Self-reported health, illness and self-care among doctors of Meerut. Indian J Commun Health. 2012;24(1):23-6.

42. Riley GJ. Understanding the stresses and strains of being a doctor. Med J Aus. 2004;181(7):350-3.

Disclaimer: None to declare.

Conflict of Interest: None to declare.

Funding Sources: None to declare. 